\title{
Mitogen-activated protein kinases (MAPKs) are modulated during in vitro and in vivo infection with the intracellular bacterium Burkholderia pseudomallei
}

\author{
R. V. D'Elia ${ }^{1}$ • R. J. Saint ${ }^{1}$ - S. L. Newstead ${ }^{1}$ - G. C. Clark ${ }^{1}$ • H. S. Atkins ${ }^{1,2}$
}

Received: 5 April 2017 / Accepted: 4 June 2017 / Published online: 30 August 2017

(C) The Author(s) 2017. This article is an open access publication

\begin{abstract}
Burkholderia pseudomallei is a Gram-negative intracellular bacterium that causes the disease melioidosis. The disease can be fatal if left untreated or when antibiotic therapy is delayed and total clearance of the pathogen from the host is often not accomplished with current therapies. Thus, new therapeutic approaches for the treatment of infections caused by B. pseudomallei are required. To better understand host responses to B. pseudomallei infection, the activation of key proteins involved in the TLR inflammatory cascade was measured by western blotting. Activation of the mitogen-activated protein kinases (MAPKs) p38 and ERK were both significantly altered during both in vitro and in vivo infection. In considering an approach for therapy of B. pseudomallei infection the inhibition of ERK was achieved in vitro using the inhibitor PD0325901, along with decreased TNF- $\alpha$ production. However, the reduction in phosphorylated ERK and TNF- $\alpha$ release did not correspond with decreased bacterial replication or enhance clearance from infected macrophages. Despite this apparent lack of effect on the intracellular growth of $B$. pseudomallei in vitro, it is not clear what effect inhibition of ERK activation might have on outcome of disease in vivo. It may be that decreasing the levels of TNF- $\alpha$ in vivo could aid in reducing the overactive immune response that is known to ensue following B. pseudomallei infection, thereby increasing host survival.
\end{abstract}

(c) Crown Copyright 2017. Published with the permission of the Defence Science and Technology Laboratory on behalf of the Controller of HMSO.

\section{R. V. D'Elia}

rvdelia@dstl.gov.uk

1 CBR Division, Defence Science and Technology Laboratory, Porton Down, Salisbury SP4 0JQ, UK

2 University of Exeter, Exeter, UK

\section{Introduction}

The innate immune response is one of the first lines of defence from infection triggered by a range of host-pathogen interactions. The first step is represented by the binding of pathogen associated molecular patterns (PAMPs; e.g. lipids, proteins, nucleic acids) to pattern recognition receptors (PRRs) such as Retinoic acid (RIG)-like receptors, Nodlike receptors (NLRs) and Toll-like receptors (TLRs) which subsequently induce signalling cascades generating immune responses [1-3].

Numerous human TLRs have been identified and shown to be expressed on various cell types including dendritic cells, neutrophils, alveolar macrophages and epithelial cells [4-7]. TLRs detect specific sets of PAMPs (e.g. TLR2 detect lipoprotein, TLR4 detect lipopolysaccharide; LPS). These TLRs play an important role in the development of numerous infectious diseases including melioidosis caused by the Gramnegative bacterium Burkholderia pseudomallei. Specifically, the TLR2 and TLR4 pathway (including the downstream inflammatory cascade and soluble factor proinflammatory responses) has been demonstrated to be important in disease formation both within in vitro cellular, knock-out and wild type experimental models of infection and within human cases of melioidosis [8-14].

Production of pro-inflammatory cytokine and chemokines requires both the activation and binding of TLRs along with the subsequent activation of multiple protein-protein complexes via two major signalling pathways: MyD88 and TRIF [15]. The activation/phosphorylation of mitogen-activated protein kinases (MAPKs) downstream of MyD88 and TRIF converts extracellular stimulations to intracellular responses via cascade proteins such as p38, ERK and JNK required in order to mount a host response during bacterial and viral infections [16-19]. The expression of p38 and ERK in Raw 
264.7 macrophages infected B. pseudomallei strain E8 has previously been reported [20] and, in addition, the inhibition of p38 was found to reduce the invasion of human alveolar lung epithelial cells by B. pseudomallei strain 844 [21]. Here we sought to build upon these reports by determining the expression and activation of the key MAPKs p38 and ERK in vitro and, uniquely, to validate these responses in vivo within a mouse model of infection for B. pseudomallei strain K96543. The work aimed to determine whether manipulation of MAPKs offers potential as a novel therapeutic strategy for treating melioidosis.

\section{Materials and methods}

\section{Bacterial culture}

B. pseudomallei strain K96243 was cultured from frozen stocks in L-broth at $37^{\circ} \mathrm{C}$ overnight with shaking. Subsequently, the suspension was adjusted using phosphatebuffered saline (PBS) to an optical density at $600 \mathrm{~nm}$ of 0.35 , with an estimated bacterial density of approximately $1 \times 10^{8}$ colony forming units (CFU) per ml. Bacteria were enumerated on agar plates following serial dilution (1:10) of samples.

\section{In vivo model of infection with $B$. pseudomallei}

Six-to-eight week old female BALB/c mice (Charles River, UK) were transferred to a class III rigid isolator and given unlimited access to food and water. Mice were challenged with $460 \mathrm{CFU}$ (calculated retained dose) of B. pseudomallei strain K96243 by the aerosol route using the Henderson apparatus [22] and a Collison nebuliser. Mice were checked twice daily and scored for clinical symptoms to identify suitable humane end points. Groups of five mice were culled at 0 , $3,10,24$ and $36 \mathrm{~h}$ post-infection and the lungs were removed and homogenised through a $40-\mu \mathrm{m}$ cell sieve before filter sterilisation through a $0.2-\mu \mathrm{m}$ syringe filter. The activation of signalling factors and the pro-inflammatory cytokine response was assessed in the homogenised and sterilised lung samples at each time point. All animal studies were carried out in accordance with the UK Scientific Procedures Act (1986).

\section{In vitro macrophage model of infection}

The murine alveolar macrophage-like MH-S cell line was obtained from the European Collection of Cell Cultures (ECACC). Cells were maintained in endotoxin-free Roswell Park Memorial Institute medium (RPMI) (Gibco) supplemented with $10 \%$ FCS (Gibco) and $2 \mathrm{mM} \mathrm{L-glutamine}$ (Sigma). MH-S cells were seeded into 6-well plates at approximately $1 \times 10^{6}$ cells $/ \mathrm{ml}$ and incubated overnight at $37^{\circ} \mathrm{C}$. The supernatants were removed and replaced with $1.5 \mathrm{ml}$ of
B. pseudomallei at an MOI of 10. Plates were incubated at $37^{\circ} \mathrm{C}$ for $30 \mathrm{~min}$ to allow for internalisation of the bacteria and then the supernatants were removed and replaced with $1.5 \mathrm{ml}$ of fresh media. The plates were incubated at $37{ }^{\circ} \mathrm{C}$ and, at a range of time points post-infection, supernatants were removed and stored at $-20{ }^{\circ} \mathrm{C}$ for cytokine analysis. The cells were washed once with chilled PBS and then lysed by adding $350 \mu$ PhosphoSafe ${ }^{\mathrm{TM}}$ extraction reagent (Merck) and incubating on ice for $5 \mathrm{~min}$. The cellular lysates were used for either bacterial enumeration on agar plates or centrifuged at $13,000 \mathrm{rpm}$ for $5 \mathrm{~min}$ to remove cell debris before being stored at $-20^{\circ} \mathrm{C}$ for subsequent analysis by western blotting.

\section{ERK inhibition assay}

MH-S cells were infected with $B$. pseudomallei at an MOI of 10 (equivalent to $t=-30 \mathrm{~min}$ ) and the cells were allowed to internalise bacteria for a further $30 \mathrm{~min}$. Control cells were left uninfected (naïve). The media was removed, cells were washed with PBS and fresh media applied (equivalent to $t=0 \mathrm{~h}$ ). The ERK inhibitor PD0325901 (InvivoGen@0.05 $\mu \mathrm{M}$ ) was added to the cells at either $0 \mathrm{~h}$ or $2 \mathrm{~h}$ after the cells were washed of non-internalised bacteria. At multiple time points after infection, supernatants and cell lysates were collected for cytokine analysis, screening for signalling protein activation and bacterial enumeration.

\section{Detection of intracellular proteins via western blotting}

Proteins were transferred from polyacrylamide gels onto Invitrolon $^{\mathrm{TM}}$ Polyvinylidene fluoride (PVDF) membranes (Invitrogen, UK) using a Novex ${ }^{\circledR}$ Semi-Dry Blotter (Invitrogen, UK) according to manufacturer's instructions. Methods followed previously published work [23] with the following specific primary antibodies (p38: p38 p38 $\alpha$ MAPKinase \#9218, P-p38: Phospho-p38 MAPKinase \#9211, ERK-1: p44 MAPKinase \#4372, ERK-2: p42 MAPKinase \#9108 and P-ERK-1/2 Thr202/ Tyr204: Phospho-p44/42 MAPK \#9101, New England Biolabs, UK). IRAK-1 (Abcam, ab238), TAK-1 \#4505, SAPK/JNK \#9252, IKK- $\alpha$ \#2682, IKK- $\beta$ \#2684, IKK- $\gamma$ $\# 2685$, IKB $\alpha \# 9242$ and IKB $\beta \# 9248$ (New England Biolabs, UK) were also tested but data is not shown. The films were computationally analysed by densitometry which allocates a value to each band relating to its size and optical density, using a GS-800 Imaging Densitometer (Bio-Rad, US) combined with Quantity One ${ }^{\circledR}$ analysis software v 4.2.1 (Bio-Rad, US). Data was normalised to the $\beta$-actin (\#4967, New England Biolabs) value from the same sample. 


\section{Measurement of soluble inflammatory markers}

Levels of IFN- $\gamma$, IL-6, IL-10, IL-12p70, TNF and MCP-1 in both in vitro and in vivo infection samples were measured via Cytometric Bead Array (Becton Dickinson ${ }^{\mathrm{TM}}$ ) in accordance with manufacturer's instructions, with the additional initial step of fixing the lung samples in $4 \%$ paraformaldehyde in PBS for at least $24 \mathrm{~h}$ at $4{ }^{\circ} \mathrm{C}$. Briefly, following fixing, samples were incubated with the combined capture bead cocktail, and PE detection antibodies for $2 \mathrm{~h}$. Samples were washed and resuspended in FACS buffer. Cytokine concentrations were measured via quantification of PE fluorescence of samples in reference to a standard curve using a BD FACS CANTO flow cytometer (Becton Dickinson ${ }^{\mathrm{TM}}$ ).

\section{Statistical analysis}

All transformations of data and statistical tests were performed using GraphPad Prism ${ }^{\circledR} 5.01$ software. Data from cytometric bead arrays were analysed using PRISM, by fitting a quadratic regression to the standard curves and reading the samples as unknowns.

\section{Results}

\section{In vitro response to $B$. pseudomallei infection}

As the lung is the primary organ associated with an inhalational B. pseudomallei infection, with as few as ten CFU causing disease via this route [24], a lung-derived (MH-S) cell line was used to determine the in vitro response to infection with B. pseudomallei strain K96423. We previously showed MH-S cells to produce a similar response to ex vivo lung cells and thus they were considered an appropriate initial model [23, 25]. Cells were infected with B. pseudomallei and at multiple time points post-infection the bacteria were enumerated, signalling protein activation was measured in cell lysates and the pro-inflammatory response was measured in cell supernatants (Fig. 1). Bacterial numbers decreased in the first $2 \mathrm{~h}$ following infection and subsequently increased through to $24 \mathrm{~h}$ (Fig. 1a). B. pseudomallei infection induced a rapid but transient increase in P-p38 at $0 \mathrm{~h}$ (30 min after infection) which was suppressed at $0.08 \mathrm{~h}$ (5 min) (Fig. 1b). A second increase in P-p38 occurred at $1.5 \mathrm{~h}$ and this activation was sustained to the $6 \mathrm{~h}$ time point. Another MAPK protein, ERK-1/2, showed a similar bi-phasic activation response comprising an early transient activation followed by a late sustained activation (Fig. 1c and d). Of the six cytokines screened for only three (MCP-1, TNF and IL-6) were found to be produced during infection (Fig. 1e); IFN- $\gamma$, IL-10 and IL-12p70 were not detected. MCP-1 was rapidly secreted during the early stages of infection and reached maximal levels of detection $(5000 \mathrm{\rho g} / \mathrm{ml}$ in the assay used) by $4 \mathrm{~h}$. TNF was secreted at a slower rate than MCP-1 but, by $24 \mathrm{~h}$ post-infection, was detected at $\sim 2500 \rho \mathrm{g} /$ $\mathrm{ml}$. In comparison, IL-6 was not readily secreted and was not elevated above baseline levels at $4 \mathrm{~h}$ and $6 \mathrm{~h}$ time points.

\section{In vivo response to $B$. pseudomallei infection}

To determine whether the bi-phasic activation of ERK and p38 observed in vitro within MH-S cells was mirrored in vivo, Balb/c mice were infected with $B$. pseudomallei K96423 via the intranasal route. At set time points mice were culled and the activation of signalling proteins within lung homogenates was determined by western blotting. In contrast to the in vitro infection of MH-S cells, B. pseudomallei infection of Balb/c mice caused no detectable increase in P-p38 activation (Fig. 2a), although a trend towards activation was noted. Corresponding with the in vitro results $B$. pseudomalle $i$ infection caused a transient increase in P-ERK activation at $10 \mathrm{~h}$ post-infection followed by a second peak at $36 \mathrm{~h}$ postinfection (Fig. $2 \mathrm{~b}$ and c). Consistent with the in vitro data, the TLR signalling cascade proteins IRAK-1, TAK-1, SAPK/JNK, IKK- $\alpha$, IKK- $\beta$, IKK- $\gamma$, IKB $\alpha$ and I $\mathrm{KB} \beta$ were not found to be significantly activated compared to the control group (data not shown).

\section{Effects of the inhibition of ERK activation by PD0325901 during infection}

Previous studies have observed that sustained ERK activation can lead to host cell apoptosis [26] and is used as a mechanism of viral propagation for the herpes simplex virus type 2 (HSV-2) [17]. A conceivable therapeutic strategy for treating a highly virulent intracellular bacterial pathogen such as $B$. pseudomallei might therefore be to inhibit ERK activation in order to re-balance the immune response and aid the resolution of infection. Several inhibitors of MAPKs have previously been assessed in vitro and in vivo with PD0325901 demonstrated to be a highly specific, potent ERK1/2 inhibitor [27]. In order to determine the effect of in vitro ERK inhibition, infected MH-S cells were treated with the PD0325901 inhibitor at $0 \mathrm{~h}$ (30 min after initial B. pseudomallei infection) or at $2 \mathrm{~h}$ (post-infection). When the cells were treated immediately after infection (i.e. at $0 \mathrm{~h}$ ) there was a significant reduction in the phosphorylated levels of ERK at $4 \mathrm{~h}$ postinfection when compared to untreated controls $(p<0.05)$. In comparison, when PD0325901 treatment was delayed until $2 \mathrm{~h}$ post-infection the presence of phosphorylated ERK at $4 \mathrm{~h}$ was not significantly different to untreated control cells (Fig. 3a and b). To provide some assurance that PD0325901 was inhibiting the activation of ERK proteins, as opposed to other structurally homologous MAPKs, the activation of p38 was also measured. 
Fig. 1 Characterisation of the in vitro response to

B. pseudomallei. MH-S cells were infected with $B$. pseudomallei K96423 at an MOI of 10 and incubated for $30 \mathrm{~min}$ at $37^{\circ} \mathrm{C}$ to allow internalisation of the bacteria. At various time points after infection bacteria were enumerated on LB plates (a) and levels of P-p38 (b), P-ERK-1 (c), and PERK-2 (d) were determined in cell lysates by western blotting. Levels of TNF, MCP-1 and IL-6 were measured in cell supernatants via CBA (e). In all cases, data shown is the combination of three independent experiments. Significant differences from naïve samples were determined using a one-tailed, unpaired t-test $(*=p<0.05)$. Error bars show $95 \%$ confidence intervals. Western blot image: $\mathrm{L}-$ MagicMark ${ }^{\mathrm{TM}}$ ladder; $\mathrm{N}$ - naïve; $+\mathrm{ve}$ - positive control a
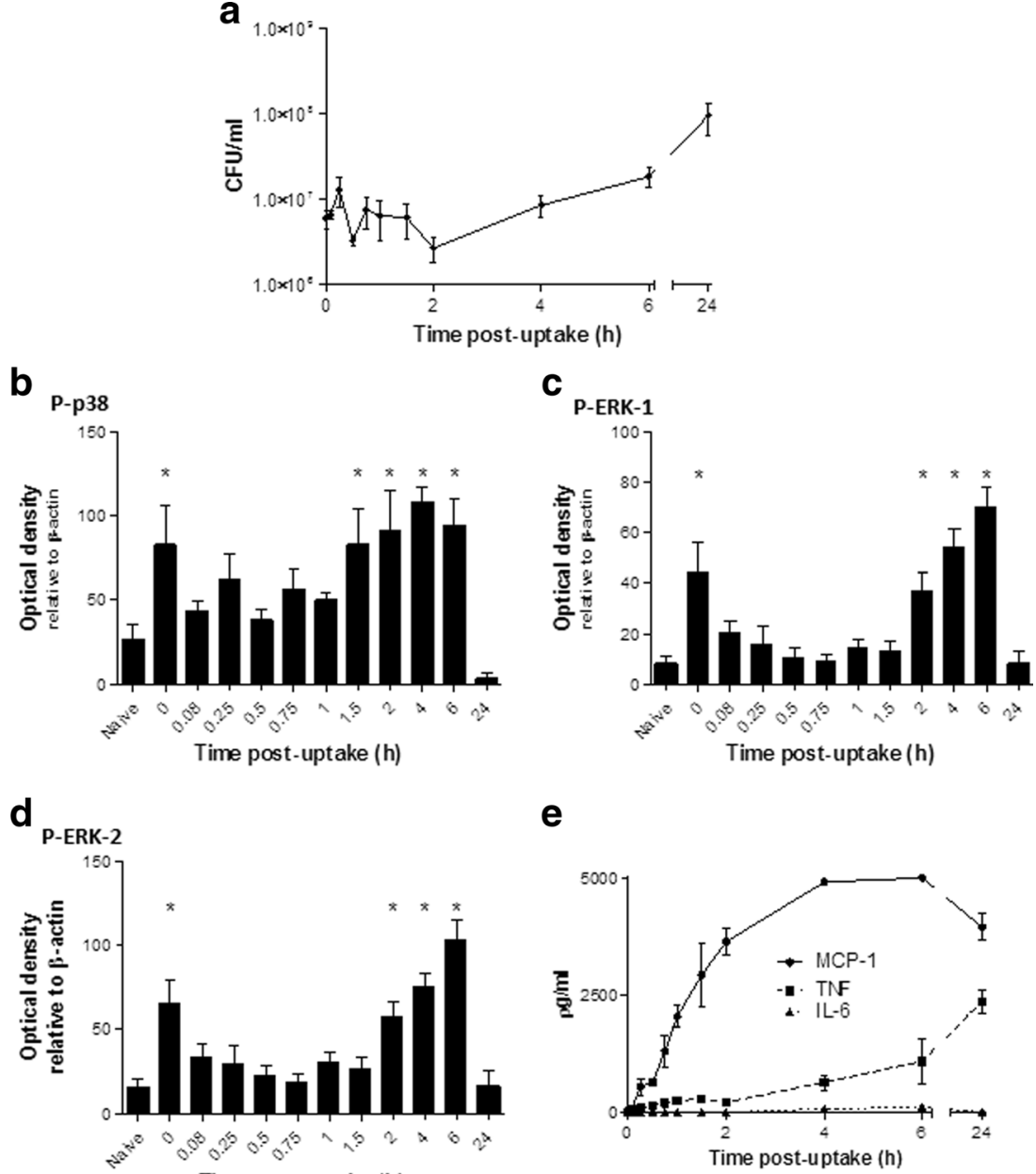

e

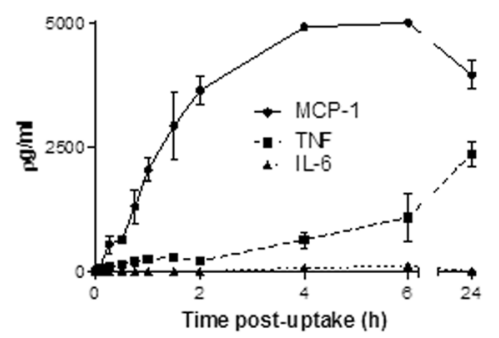

Time post-uptake (h)

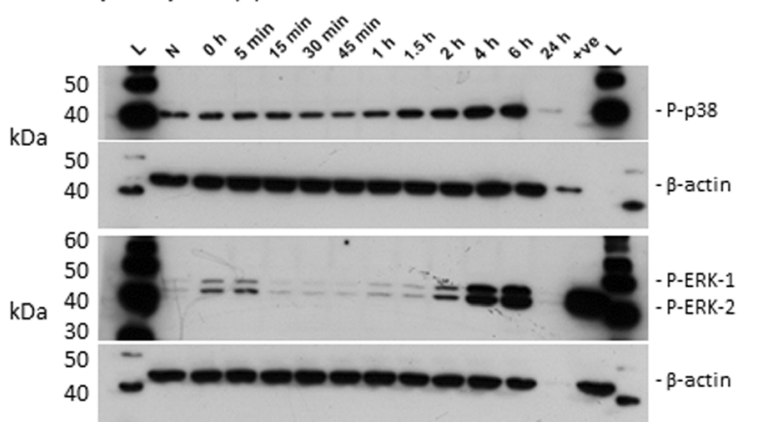

No significant inhibition of p38 activation was observed in cells treated with PD0325901 when compared to untreated controls (Fig. 3c). Since ERK activation was inhibited in this assay system, the indirect effects of ERK inhibition could be determined by measuring inflammatory cytokine secretion. Cells with PD0325901 administered at $0 \mathrm{~h}$ had significantly decreased TNF secretion after $4 \mathrm{~h}(p<0.05)$ when compared to untreated controls (Fig. 3d). In contrast, the administration of PD0325901 at $2 \mathrm{~h}$ had no effect on TNF secretion. The presence of other inflammatory cytokines including IL-6, MCP-1, IFN-y, IL-10 and IL-12 were not significantly altered following treatment at either time point (data not shown).
Bacteria were enumerated within the MH-S cells in order to determine whether the effects of reducing ERK activation via PD0325901 administration led to differences in the intracellular growth and survival of $B$. pseudomallei. In this study no significant difference in intracellular bacterial numbers was detected within MH-S cells despite PD0325901 treatment (Fig. 3e).

\section{Discussion}

The identification of the specific signalling proteins involved in the response to an infection can provide important 
Fig. 2 Characterisation of p38 and ERK in vivo response to B. pseudomallei. Groups of five mice were challenged with $460 \mathrm{CFU}$ of $B$. pseudomallei K96423 via the intranasal route and five mice were culled at each time point. Levels of P-p38 (a), PERK-1 (b) and P-ERK-2 (c) in the lungs of infected mice were determined at $0,3,10,24$ and $36 \mathrm{~h}$ after infection. Significant differences from naïve samples were determined using a one-tailed, unpaired t-test $(*=p<0.05)$. Error bars show $95 \%$ confidence intervals. Western blot image: $\mathrm{L}-$ MagicMark $^{\mathrm{TM}}$ ladder; $\mathrm{N}$ - naïve; $+\mathrm{ve}$ - positive control a

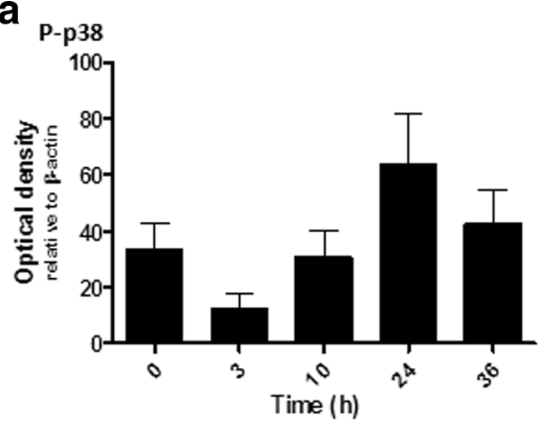

b

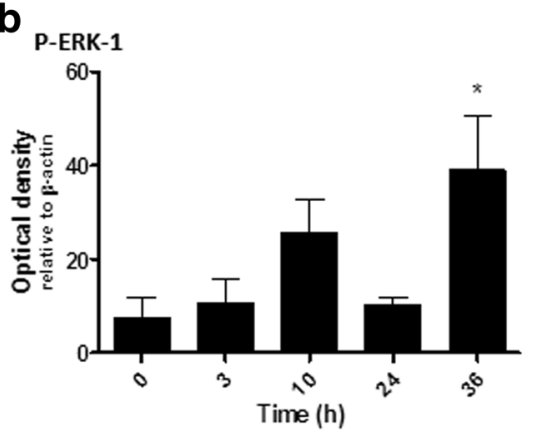

C P-ERK-2

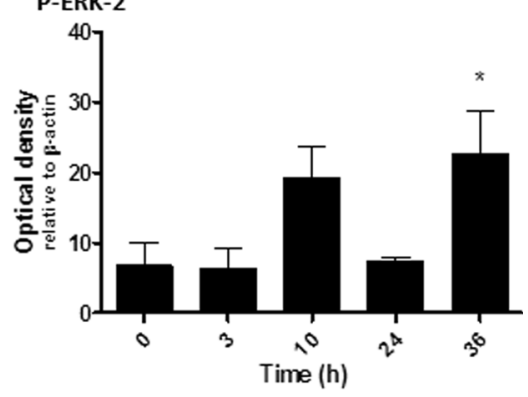

$\mathrm{kDa}$

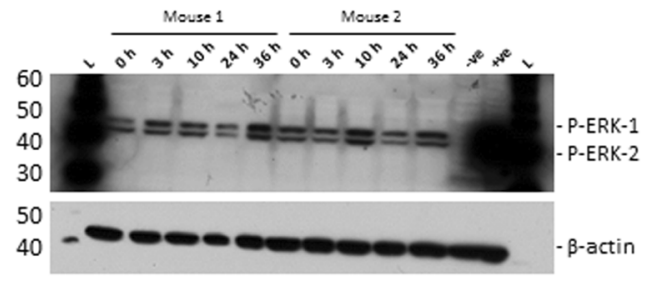

$\mathrm{kDa}$

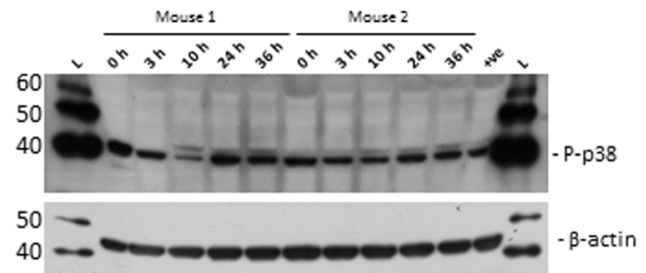

information concerning the pathogenesis, mechanisms of survival and immune evasion used by pathogens [28]. This study has demonstrated that intracellular B. pseudomallei triggered temporal changes in the phosphorylation states of two MAPKs, p38 and ERK, and that these same patterns were also identified in vivo following the pulmonary infection of Balb/c mice with organism. In particular, we have shown significant increases in P-ERK in the latter stages of infection.

By investigating the temporal dynamics of signalling protein activation during infection of MH-S cells an initial increase in both P-p38 and P-ERK1/2 was evident following a $30 \mathrm{~min}$ incubation with the bacteria $(t=0 \mathrm{~h})$. These proteins were quickly dephosphorylated returning to naive levels of activation until $2 \mathrm{~h}$ post-infection, whereupon a rapid and sustained activation of these kinases occurred. A recently published study also highlighted the potential importance of the phosphorylation of p38 and ERK following B. pseudomallei infection [20]. However, the previous study used a soil isolated strain E8 of B. pseudomallei and RAW 264.7 cells, whilst here we have used a clinical isolate in strain K96243 and an alveolar macrophage cell line (i.e. more relevant to pulmonary melioidosis). Crucially, our study has measured the phosphorylation state of p38 and ERK over a longer time course of infection with samples taken more frequently, allowing a greater characterisation of the biphasic nature of the phosphorylation state of $\mathrm{p} 38$ and ERK which may be essential in determining an optimum time to initiate a therapeutic intervention.

The temporal dynamics of ERK activation, in particular, may provide important information with respect to the pathogenesis of B. pseudomallei. Transient activation of ERK corresponds with host cell survival strategies whereas sustained activation is associated with cell death mechanisms [29, 30]. The transient activation of $\mathrm{p} 38$ and ERK demonstrated here indicates that during the early stages of infection with 
Fig. 3 Treatment of infection with the ERK inhibitor, PD0325901. MH-S cells were infected with $B$. pseudomallei K96423 at an MOI of 10 and incubated for $30 \mathrm{~min}$ at $37^{\circ} \mathrm{C}$ to allow uptake of the bacteria. The cells were treated with PBS (untreated), treated with PD0325901 at $0 \mathrm{~h}$ or treated with PD0325901 at $2 \mathrm{~h}$ after infection. Levels of P-ERK-1 (a), P-ERK-2 (b) and P-p38 (c) were determined in cell lysates collected at $4 \mathrm{~h}$ after infection by western blotting. Levels of TNF were measured in the cell supernatant via CBA at three time points after infection (d). Bacteria were enumerated on LB plates (e). In all cases, data shown is the combination of three independent experiments. Significant differences from naïve samples were determined using a one-tailed, unpaired t-test $(*=p<0.05)$. Error bars show $95 \%$ confidence intervals a

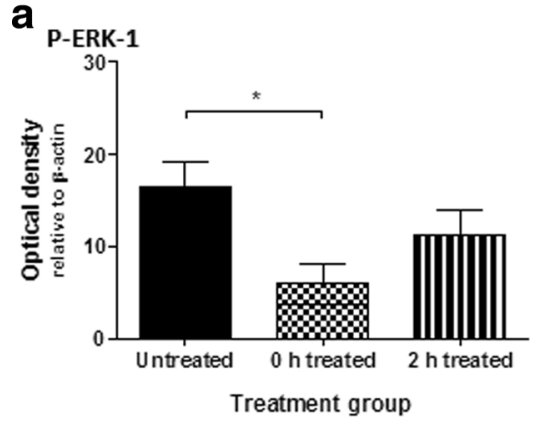

C

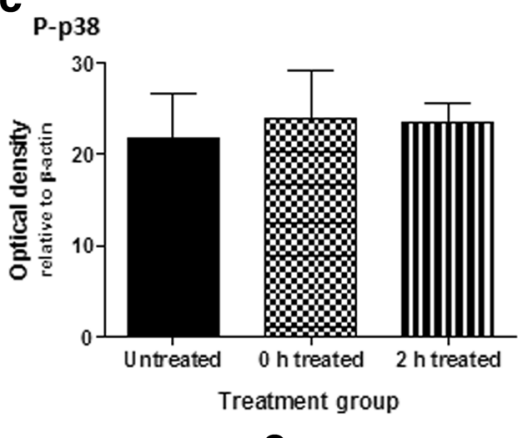

e

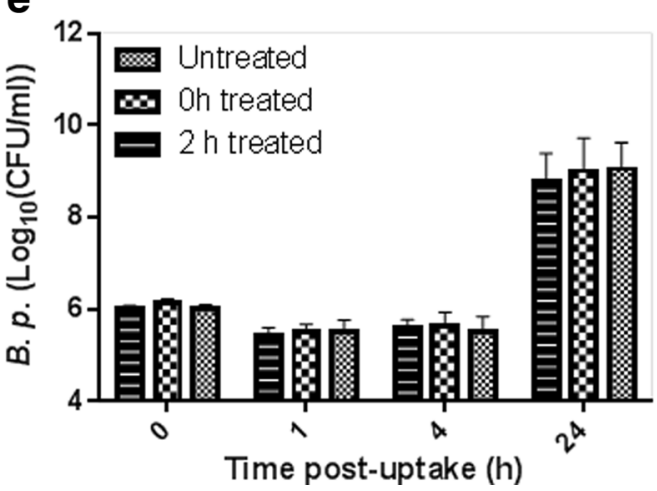

b P-ERK-2

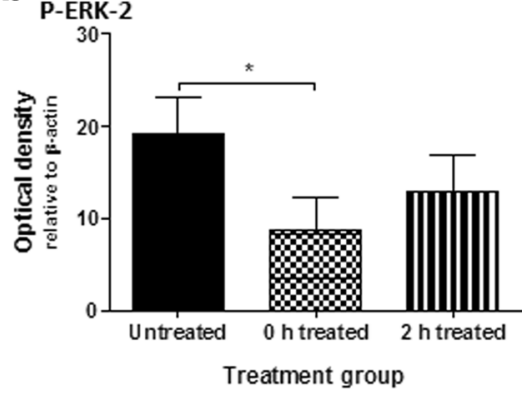

d

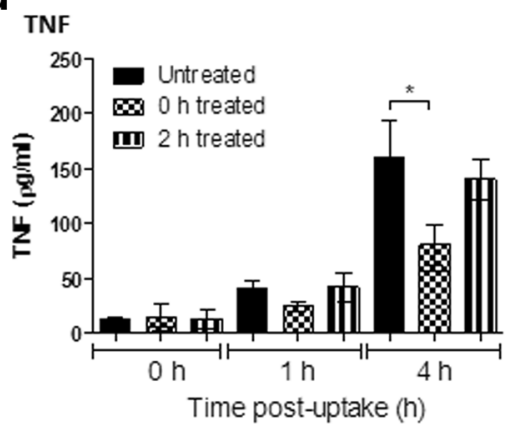

B. pseudomallei, host cells may adopt cell survival strategies. During latter stages of infection, the host cells may be in the process of cell death, as indicated by sustained ERK activation. This pattern of signalling protein activation points towards $B$. pseudomallei regulating ERK in order to delay the induction of cellular apoptosis, allowing the bacteria increased time to proliferate within infected cells and/or invade further host cells. The modulation of apoptotic pathways has been observed in other infectious diseases. Chlamydiae prevent the induction of apoptosis through modulation of ERK signalling pathway enabling the bacteria to complete their obligate intracellular growth cycle [31]. Helicobacter pylori can induce the formation of an apoptosis complex during infection via ERK signalling [32]. B. pseudomallei may also therefore modulate ERK signalling in order to prolong the survival of the host cell.

Additionally, we demonstrated that MCP-1 was rapidly secreted and TNF- $\alpha$ exhibited a more gradual increase throughout the infection of MH-S cells. These two cytokines are key pro-inflammatory markers of infection and have been reported to be upregulated during Burkholderia infection [33]. The activation of ERK is required for the transport of TNF- $\alpha$ mRNA from the nucleus into the cytoplasm and activation of p38, via its downstream substrate MK-2, is linked to increased TNF mRNA stability ([34]) suggesting that the differing phosphorylation states of p38 and ERK seen during $B$. pseudomallei infection are linked to the changes seen in TNF- $\alpha$ secretion.

Finally, our research also aimed to evaluate the importance of ERK in coordinating the immune response to B. pseudomallei infection through the use of the inhibitor PD0325901. To our knowledge, this is the first report to describe ERK inhibition in the context of infection with B. pseudomallei. We found the phosphorylation of both ERK-1 and ERK-2 within infected MH-S cells was significantly decreased in the presence of the inhibitor. However, no change to P-p38 expression was detected, indicating that PD0325901 did not have a more 
widespread effect on immune signalling. We found that ERK inhibition following PD0325901 administration led to decreased levels of TNF- $\alpha$ secretion in the supernatant of infected MHS cells. However, despite the decreased ERK activation and reduced TNF- $\alpha$ production observed in PD0325901-treated B. pseudomallei-infected cells, this did not afford protection from the bacteria since both treatment regimens with the inhibitor resulted in similar intracellular bacterial counts to untreated cells. It is perhaps not surprising that the administration of a single ERK inhibitor did not alter bacterial clearance of $B$. pseudomallei which has numerous mechanisms for virulence and, in addition, the signalling pathways are complex with both positive and negative feedback mechanisms. There may be sufficient redundancy in the immune response to mitigate the effects of PD0325901 treatment (e.g. ERK has been demonstrated to be activated by both MEK-1 and MEK-2 [29]).

In conclusion, it is clear that $B$. pseudomallei infection causes numerous alterations in proteins involved in intracellular inflammatory cascades. In particularly, we identified that the activation states of both ERK and p38 kinases changed over time as a result of $B$. pseudomallei infection and that these in vitro effects were mirrored within an in vivo context. Specifically, inhibiting ERK activation had no significant effect on the outcome within in vitro models of infection for B. pseudomallei and therefore in vivo efficacy was not pursued. More effective approaches are likely to require either the targeting of multiple proteins within a TLR pathway cascade (i.e. overcoming potential redundancies) or alternatively through the use of combination therapies that involve the use of specific inhibitors along with traditional treatments (e.g. antibiotics).

Acknowledgements The authors would like to thank the animal technicians that assisted with these studies and the UK Ministry of Defence for funding this work.

\section{Compliance with ethical standards}

Funding This work was funded by the UK Ministry of Defence.

Conflict of interest To the authors knowledge there is no conflict of interest arising from the publication of this manuscript.

Ethical approval All procedures performed in studies involving animals were in accordance with the ethical standards of the institution or practice at which the studies were conducted.

\section{Informed consent Not applicable.}

Open Access This article is distributed under the terms of the Creative Commons Attribution 4.0 International License (http:// creativecommons.org/licenses/by/4.0/), which permits unrestricted use, distribution, and reproduction in any medium, provided you give appropriate credit to the original author(s) and the source, provide a link to the Creative Commons license, and indicate if changes were made.

\section{References}

1. Mogensen TH (2009) Pathogen recognition and inflammatory signaling in innate immune defenses. Clin Microbiol Rev 22:240-273

2. Creagh EM, O'Neill LAJ (2006) TLRs, NLRs and RLRs: a trinity of pathogen sensors that co-operate in innate immunity. Trends Immunol 27:352-357

3. Schnare M, Barton GM, Holt AC, Takeda K, Akira S et al (2001) Toll-like receptors control activation of adaptive immune responses. Nat Immunol 2:947-950

4. Hirata N, Yanagawa Y, Ebihara T, Seya T, Uematsu S et al (2008) Selective synergy in anti-inflammatory cytokine production upon cooperated signaling via TLR4 and TLR2 in murine conventional dendritic cells. Mol Immunol 45:2734-2742

5. Droemann D, Goldmann T, Branscheid D, Clark R, Dalhoff K et al (2003) Toll-like receptor 2 is expressed by alveolar epithelial cells type II and macrophages in the human lung. Histochem Cell Biol 119:103-108

6. Guillot L, Medjane S, Le-Barillec K, Balloy V, Danel C et al (2004) Response of human pulmonary epithelial cells to lipopolysaccharide involves toll-like receptor 4 (TLR4)-dependent signaling pathways - evidence for an intracellular compartmentalization of TLR4. J Biol Chem 279:2712-2718

7. David J, Bell RE, Clark GC (2015) Mechanisms of disease: hostpathogen interactions between Burkholderia species and lung epithelial cells. Front Cell Infect Microbiol 5:80

8. Wiersinga WJ, Wieland CW, Dessing MC, Chantratita N, Cheng AC et al (2007) Toll-like receptor 2 impairs host defense in gramnegative sepsis caused by Burkholderia pseudomallei (Melioidosis). PLoS Med 4:1268-1280

9. Joost Wiersinga W, Dessing MC, van der Poll T (2008) Geneexpression profiles in murine melioidosis. Microbes Infect 10 : 868-877

10. Conejero L, Potempa K, Graham CM, Spink N, Blankley S et al (2015) The blood transcriptome of experimental Melioidosis reflects disease severity and shows considerable similarity with the human disease. J Immunol 195:3248-3261

11. Wiersinga WJ, van't Veer C, van den Pangaart PS, Dondorp AM, Day NP et al (2009) Immunosuppression associated with interleukin-1R-associated-kinase-M upregulation predicts mortality in gram-negative sepsis (melioidosis). Crit Care Med 37:569-576

12. West TE, Ernst RK, Jansson-Hutson MJ, Skerrett SJ (2008) Activation of toll-like receptors by Burkholderia pseudomallei. BMC Immunol 9:46

13. Brett PJ, Burtnick MN, Snyder DS, Shannon JG, Azadi P et al (2007) Burkholderia mallei expresses a unique lipopolysaccharide mixture that is a potent activator of human toll-like receptor 4 complexes. Mol Microbiol 63:379-390

14. West T, Hawn T, Skerrett S (2009) Toll-like receptor signaling in airborne Burkholderia thailandensis infection. Infect Immun 77(12):5612-5622

15. Oda K, Kitano H (2006) A comprehensive map of the toll-like receptor signaling network. Mol Syst Biol 2:2006.0015

16. Welsh CT, Summersgill JT, Miller RD (2004) Increases in c-jun nterminal kinase/stress-activated protein kinase and p38 activity in monocyte-derived macrophages following the uptake of Legionella pneumophila. Infect Immun 72:1512-1518

17. Zhang H, Feng H, Luo LQ, Zhou Q, Luo ZJ et al (2010) Distinct effects of knocking down MEK1 and MEK2 on replication of herpes simplex virus type 2. Virus Res 150:22-27 
18. Souza C, Evanson O, Weiss D (2007) Role of the mitogen-activated protein kinase pathway in the differential response of bovine monocytes to Mycobacterium avium subsp. paratuberculosis and Mycobacterium avium subsp. avium. Microbes Infect 9:1545-1552

19. Roux PP, Blenis J (2004) ERK and p38 MAPK-activated protein kinases: a family of protein kinases with diverse biological functions. Microbiol Mol Biol Rev 68:320-344

20. Chiang CY, Ulrich RL, Ulrich MP, Eaton B, Ojeda JF et al (2015) Characterization of the murine macrophage response to infection with virulent and avirulent Burkholderia species. BMC Microbiol 15:259

21. Sim SH, Liu Y, Wang D, Novem V, Sivalingam SP et al (2009) Innate immune responses of pulmonary epithelial cells to Burkholderia pseudomallei infection. PLoS One 4:e7308

22. Druett HA (1969) A mobile form of the Henderson apparatus. J Hyg (Lond) 67:437-448

23. Saint RJ, D'Elia RV, Bryant C, Clark GC, Atkins HS (2016) Mitogen-activated protein kinases (MAPKs) are modulated during Francisella tularensis infection, but inhibition of extracellularsignal-regulated kinases (ERKs) is of limited therapeutic benefit. Eur J Clin Microbiol Infect Dis 35:2015-2024

24. Lever MS, Nelson M, Stagg AJ, Beedham RJ, Simpson AJH (2009) Experimental acute respiratory Burkholderia pseudomallei infection in BALB/c mice. Int J Exp Pathol 90:16-25

25. D'Elia R, Jenner DC, Laws TR, Stokes MGM, Jackson MC et al (2011) Inhibition of Francisella tularensis LVS infection of macrophages results in a reduced inflammatory response: evaluation of a therapeutic strategy for intracellular bacteria. FEMS Immunol Med Microbiol 62:348-361
26. Murphy LO, Blenis J (2006) MAPK signal specificity: the right place at the right time. Trends Biochem Sci 31:268-275

27. Kohno M, Pouyssegur J (2006) Targeting the ERK signaling pathway in cancer therapy. Ann Med 38:200-211

28. Schmid-Hempel P (2008) Parasite immune evasion: a momentous molecular war. Trends Ecol Evol 23:318-326

29. Ramos JW (2008) The regulation of extracellular signal-regulated kinase (ERK) in mammalian cells. Int J Biochem Cell Biol 40(12): 2707-2719

30. Hrstka R, Stulik J, Vojtesek B (2005) The role of MAPK signal pathways during Francisella tularensis LVS infection-induced apoptosis in murine macrophages. Microbes Infect 7:619-625

31. Du K, Zheng Q, Zhou M, Zhu L, Ai B et al (2011) Chlamydial Antiapoptotic activity involves activation of the Raf/MEK/ERK survival pathway. Curr Microbiol 63:341-346

32. Asim M, Chaturvedi R, Hoge S, Lewis ND, Singh K et al (2010) Helicobacter pylori induces ERK-dependent formation of a Phospho-c-Fos.C-Jun activator protein-1 complex that causes apoptosis in macrophages. J Biol Chem 285:20343-20357

33. Laws TR, Smither SJ, Lukaszewski RA, Atkins HS (2011) Neutrophils are the predominant cell-type to associate with Burkholderia pseudomallei in a BALB/c mouse model of respiratory melioidosis. MicrobPathog 51:471-475

34. Dumitru CD, Ceci JD, Tsatsanis C, Kontoyiannis D, Stamatakis K et al (2000) TNF-alpha induction by LPS is regulated posttranscriptionally via a Tp12/ERK-dependent pathway. Cell 103:1071-1083 